\title{
Assessment of Soil Microbes and Enzyme Activities in the Degraded Soils Adjacent to Industries and Mines and its Relation with Heavy Metal Contaminants
}

\section{K Laxminarayana ${ }^{1 *}$, Sulekha Pradhan ${ }^{2}$, M Madhumita Das ${ }^{3}$ and M Nedunchezhiyan ${ }^{1}$}

${ }^{1}$ Principal Scientist, Regional Centre, ICAR-Central Tuber Crops Research Institute, Bhubaneswar, Odisha, India

${ }^{2}$ Postgraduate, Department of Biotechnology, MITS School of Biotechnology,

Bhubaneswar, Odisha, India

${ }^{3}$ Principal Scientist, ICAR-Indian Institute of Water Management, Chandrasekharpur, Bhubaneswar, Odisha, India

*Corresponding Author: K Laxminarayana, Principal Scientist, Regional Centre, ICAR-Central Tuber Crops Research Institute, Bhubaneswar, Odisha, India.

DOI: 10.31080/ASAG.2020.04.0880
Received: July 06, 2020

Published: July 30, 2020

(C) All rights are reserved by

K Laxminarayana., et al.

\begin{abstract}
A study was undertaken to assess the microbial diversity and enzyme activities and their relationship with soil properties in the soils adjacent to chromium, iron and coal mining areas of Jajpur, Keonjhar and Jharsuguda districts and adjacent to industrial areas as well as ash ponds of thermal power plant and aluminium refinery of Angul, Koraput, Rayagada, Jagatsinghpur, Sundargarh, Bhadrak, Balasore, Mayurbhanj, Cuttack, and Ganjam districts of Odisha, India. The effluents from the mines are discharged to nearby arable lands and water bodies causing acid mine drainage. The soils of the study area are strongly acidic to slightly alkaline in reaction ( $\mathrm{pH} 4.23$ - 7.85), non saline, and having very low to high organic carbon (0.15 - 1.88\%), low to medium in available nitrogen $(\mathrm{N})$, low to high in available phosphorus $(\mathrm{P})$ and potassium (K). The soils contain toxic levels of iron (Fe), manganese (Mn), chromium (Cr), nickel ( $\mathrm{Ni})$, lead ( $\mathrm{Pb}$ ) and relatively higher status of available zinc (Zn). Highest available Fe (240.8 mg kg-1) was observed in the soils adjacent to sugar factory of Ganjam district, Mn in the soils of coal mining areas of Jharsuguda (146.0 mg kg-1), highest $\mathrm{Cr}$ (178.4 $\mathrm{mg} \mathrm{kg}^{-1}$ ) and $\mathrm{Ni}\left(12.4 \mathrm{mg} \mathrm{kg}^{-1}\right)$ in the soils of chromium mining areas of Jajpur and highest $\mathrm{Pb}\left(18.9 \mathrm{mg} \mathrm{kg}{ }^{-1}\right)$ in the bauxite mining areas of Koraput district of Odisha. However, highest available $\mathrm{Cu}\left(9.02 \mathrm{mg} \mathrm{kg}^{-1}\right)$ and Zn (6.36 mg kg-1) contents were recorded adjacent to Rourkela steel plant areas of Sundargarh district. Toxicity of heavy metals in the soils of Jagatsinghpur district led to very low biological activities in terms of dehydrogenase $\left(0.186 \mu \mathrm{g} \mathrm{TPF} \mathrm{hr} \mathrm{g}^{-1}\right)$, fluorescein diacetate $\left(0.152 \mu \mathrm{g} \mathrm{g} \mathrm{hr}^{-1}\right)$ and alkaline phosphatase $\left(9.68 \mu \mathrm{g} \mathrm{PNP} \mathrm{g}^{-1} \mathrm{hr}^{-1}\right)$. The study emphasized that toxic levels of heavy metals in these mining and industrial areas and consequently their uptake in to the plant system is very much harmful to the livestock and human beings and there is an urgent need to advocate the people in these areas to adopt proper remedial measures so as to minimize the levels of these elements in the soil-plant-animal-human chain.
\end{abstract}

Keywords: Heavy Metals; Pollutants; Mining and Industrial Areas; Microbial Diversity; Enzyme Activities; Soil Properties; Correlations 


\section{Introduction}

The state of Odisha is rich in natural resources, endowed with an abundance of mineral, forest, marine and water resources and it is India's main supplier of valuable minerals such as chromites, nickel ore, coal, bauxite, iron ore and manganese. The state accounted for 38 and 98\% of India's total production of iron and chromium ore, respectively. Sukinda valley of Odisha has the major production of chromium and is under serious threat due to the production of chromium and chromates which are known as the potential carcinogenic substances for lungs and nose cancer. Heavy metals are potentially toxic to crop plants, animals and human beings when the contaminated soils are used for crop production. Pollution of the biosphere with heavy metals due to intensive agricultural and other anthropogenic activities poses serious problems to the farming land [1]. Organic materials such as farm manures, bio-solids or composts contain higher concentration of trace elements and its usage increases the total amount of copper $(\mathrm{Cu})$, zinc $(\mathrm{Zn})$, lead $(\mathrm{Pb})$, cadmium $(\mathrm{Cd})$, iron (Fe) and manganese $(\mathrm{Mn})$ in soils [2].

Chemical compounds, entering the ecosystem as a result of different human activities, may accumulate in soil and water environments. Therefore, soil may be regarded as a long-term reservoir of pollutants, from which these compounds may be introduced to food chains or groundwater. Inappropriate and careless disposal of industrial waste often results in environmental pollution. The pollution includes point sources such as emission, effluents and solid discharge from industry, vehicle exhaustion and metal smelting or mining as well as nonpoint sources like pesticide residues or excessive use of fertilizers [3]. Each of the sources have their own damaging effects on plant, animal and human health, but those that add heavy metals to soils are of serious concern due to the persistence of these elements in the environment. They cannot be destroyed, but are only transformed from one state to another [4].

Heavy metal pollution of surface soils due to intense industrialization and urbanization has become a serious concern and accumulation of heavy metals in surface soils is affected by many environmental variables, including parent material and soil properties, as well as by human activities, such as industrial production, traffic, farming, and irrigation. Most common heavy metals produced by industrial activities are lead (Pb), mercury ( $\mathrm{Hg}$ ), cadmium (Cd), arsenic (As), chromium (Cr), manganese (Mn), iron (Fe), and zinc (Zn), and accumulated slowly in the surrounding water and arable lands. Heavy metal toxicity has an inhibitory effect on plant growth, stomata function, photosynthesis activity and accumulation of high density elements damages the root system and severely affects the microbial activities [5]. Sites near coal mining areas were heavily contaminated with heavy metals like $\mathrm{Fe}, \mathrm{Mn}, \mathrm{Zn}, \mathrm{Pb}, \mathrm{Cu}, \mathrm{Ni}, \mathrm{Cd}$ and Cr compared to the critical soil concentrations [6].

Microorganisms are the first biota that undergoes direct and indirect impacts of heavy metals. Some metals ( $\mathrm{Fe}, \mathrm{Zn}, \mathrm{Cu}, \mathrm{Ni}, \mathrm{Co}$ ) are of vital importance for many microbial activities when occur at low concentrations and are often involved in the metabolism and redox processes. Some heavy metals such as $\mathrm{Co}, \mathrm{Cu}, \mathrm{Fe}, \mathrm{Mn}, \mathrm{Mo}, \mathrm{Ni}$, $\mathrm{V}$ and $\mathrm{Zn}$ are required in minute quantities by organisms, however, excessive amounts of these elements can become harmful to organisms. Other heavy metals such as $\mathrm{Pb}, \mathrm{Cd}$, and $\mathrm{Hg}$ do not have any beneficial effect on organisms and they are very harmful to both plants and animals. Soil bacteria immobilize heavy metals and contribute higher mobility to heavy metals, whereas $\mathrm{Pb}$ and $\mathrm{Hg}$ are more readily accumulated by fungi and actinomycetes in comparison to $\mathrm{Zn}, \mathrm{Mn}, \mathrm{Cd}, \mathrm{Ni}$, and Co which make selective accumulation of heavy metals by fungi different from many bacteria and yeast. Soil fungi are sensitive to a wide variety of organic and inorganic pollutants and environmental changes. Actinomycetes are important in forming stable humus, which enhances soil structure, improves retention of soil water and nutrients. Bacteria facilitate a number of physical and biochemical alterations or reactions in soils and thereby directly or indirectly support the development of higher plants.

Soil biological activities depends on the metabolic state of soil microorganisms and the microbial activity is affected by numerous factors such as soil type, $\mathrm{pH}$ etc [7]. The activities of certain enzymes such as dehydrogenase, urease, aryl sulfatase and phosphatase have been reported as available indicators of heavy metal contamination in soil ecosystems [8]. Karaca., et al. [9] explained that activities of aryl sulphatase, galactosidase, and alkaline phosphomonoesterase in soil negatively correlated with $\mathrm{Cd}$. Hinojosa., et al. [10] reported that phosphatase, aryl sulfatase, $\beta$-glucosidase, urease, and dehydrogenase activities in soils polluted with heavy metals were less active in soils contaminated with $\mathrm{Cd}, \mathrm{Cu}, \mathrm{Pb}$, and Zn than in non-contaminated soils. The present investigation was undertaken to assess the spatial distribution of heavy metals and their relationship with microbial activities in the mining and in- 
dustrial areas in some parts of Odisha, India so as to advocate proper remedial measures for minimizing their accumulation in soil-plant-human beings.

\section{Materials and Methods}

A total of 55 surface $(0-30 \mathrm{~cm})$ soil samples were collected during 2015-18 adjacent to mines and industrial areas representing from 13 districts (Jajpur-3, Keonjhar-5, Angul-3, Koraput-2, Rayagada-3, Jagatsinghpur-6, Sundargarh-12, Jharsuguda-4, Bhadrak-2, Balasore-6, Mayurbhanj-2, Cuttack-5, and Ganjam-2) of Odisha, India. Fresh soil samples were collected from all the locations and the soil samples were sieved with $0.5 \mathrm{~mm}$ sieve by removing gravels and other waste materials, stored up to 3 weeks at $4^{\circ} \mathrm{C}$ and used for enumeration of microbes and estimation of enzyme activities. Nutrient Agar media was used for isolation of bacteria, Potato Dextrose Agar for fungi and Starch Casein Agar for actinomycetes. Soil dilution plates were prepared from fresh soil on the day of sampling. After the serial dilution, $1.0 \mathrm{ml}$ of required dilution $\left(10^{-4}\right.$ for fungi and actinomycetes and $10^{-5}$ for bacteria) was inoculated into the respective petri plates. The sample was spread over the media via a flame sterilized bent glass rod and all plates were incubated in the dark at $20^{\circ} \mathrm{C}$. After microbial colonies are readily visible $(2$ - 7 days for bacteria and fungi and 7 - 14 days for actinomycetes), the number of colonies on each plate are counted and calculated. The number of cfu g-1 dry soil was estimated by taking the soil dilution factor and soil moisture content into account. Enumeration of these colonies which develop on a specific growth medium, the number of viable cells of a particular group of microbes present in the soil can be ascertained.

Soil dehydrogenase activity (DHA) is determined by the method as described by Casida., et al [7]. The fluorescein diacetate hydrolysis assay (FDA) was determined in the fresh soils by the method as described by Green., et al [11]. Phosphatase activity was determined by the method described by Tabatabai and Bremner [12]. The air dried soils were analyzed for physico-chemical properties ( $\mathrm{pH}, \mathrm{EC}$, organic $\mathrm{C}$, available $\mathrm{N}, \mathrm{P}$ and $\mathrm{K}$ ) as per the standard methods described by Jackson [13]. Heavy metals (Fe, Cu, Mn, Zn, $\mathrm{Cr}, \mathrm{Ni}$ and $\mathrm{Pb}$ ) in the soils were estimated by using the respective electrodeless discharge lamps in Atomic Absorption Spectrophotometer [13]. Correlation coefficients were derived to establish the relationship between soil properties and microbial variables with heavy metals.

\section{Results and Discussion}

\section{Physico-chemical properties}

The $\mathrm{pH}$ of the contaminated soils through industrial effluents representing from 13 districts of Odisha, India ranged from 4.23 to 7.85 (Table 1). Relatively higher status of soil $\mathrm{pH}$ was observed in the soils of Angul ( $\mathrm{pH} 7.85$ ) followed by iron mining areas of Keonjhar (pH 7.78), while it was strongly acidic (pH 4.23) adjacent to sugar factory of Ganjam district followed by industrial areas of Jagatsinghpur district (pH 4.47). The soils of the study area are non saline $\left(0.078-1.869 \mathrm{dS} \mathrm{m}^{-1}\right)$. The soil organic carbon in the polluted soils ranged from $0.15-1.88 \%$ with a mean value of $0.71 \%$. The mean soil organic carbon content adjacent to industrial areas of Rayagada was found to be deficient $(0.43 \%)$, however, it was medium in the soils from Mayurbhanj (0.52\%), Ganjam (0.53\%), Jagatsinghpur (0.54\%), Balasore (0.55\%), Bhadrak (0.56\%) and Cuttack $(0.60 \%)$. Around $36 \%$ soils found deficient $(<0.50 \%)$, $29 \%$ soils are medium $(0.50-0.75 \%)$ and the rest of soils contain high status of organic carbon $(>0.75 \%)$. Highest mean value of organic C $(1.04 \%)$ was observed in the soils from iron mining areas of Keonjhar district followed by Jajpur (0.91\%), Koraput (0.87\%), Jharsuguda $(0.78 \%)$ and Sundargarh $(0.77 \%)$. Most of the contaminated soils of the study area are barren due to release of effluents and accumulated with organic residues led to build up of organic matter in the soils.

The available $\mathrm{N}$ in the soils of the present study area ranged from $101-385 \mathrm{~kg} \mathrm{ha}^{-1}$.with a mean value of $216 \mathrm{~kg} \mathrm{ha}^{-1}$. Around $65 \%$ of the polluted soils found deficient in available $\mathrm{N}(<250 \mathrm{~kg}$ $\left.\mathrm{ha}^{-1}\right)$ and the rest of the soils contain medium status of available $\mathrm{N}$ (250 - $500 \mathrm{~kg} \mathrm{ha}^{-1}$ ). The mean available $\mathrm{N}$ was found lowest in the soils of Bhadrak (164.9 kg ha-1), Sundargarh (165.2 kg ha-1), Balasore (181.5 $\mathrm{kg} \mathrm{ha}^{-1}$ ), Jagatsinghpur (184.6 $\mathrm{kg} \mathrm{ha}^{-1}$ ), and Mayurbhanj (185.4 $\mathrm{kg} \mathrm{ha}^{-1}$ ), while it was highest in the areas of Ganjam district (329 $\mathrm{kg} \mathrm{ha}^{-1}$ ). The results of the study indicated that the available $\mathrm{N}$ status in the degraded soils of Odisha is very low to medium. The available $\mathrm{P}$ in the mining and industrial areas ranged from 5.82 - $95.79 \mathrm{~kg} \mathrm{ha}^{-1}$ with a mean value of $29.33 \mathrm{~kg} \mathrm{ha}^{-1}$. The mean available P in the soils of Mayurbhanj district was found to be medium (11.35 kg ha-1) followed by Rayagada (15.50 kg ha-1), Balasore (16.13 kg ha-1), Bhadrak (17.71 kg ha-1), Angul (18.37 kg ha-1), Jharsuguda (21.61 kg ha-1), and Jagatsinghpur (24.10 kg ha-1). Lowest mean available $\mathrm{K}$ was noticed in the soils of Ganjam (116.5 kg ha-1), however, it was found medium in the soils of Mayurbhanj $(143.6 \mathrm{~kg}$ ha $\left.^{-1}\right)$, Balasore (171.3 $\left.\mathrm{kg} \mathrm{ha}^{-1}\right)$, Sundargarh (188.0 kg ha $\left.\mathrm{g}^{-1}\right)$, Bhadrak (189.3 kg ha-1), Angul (189.7 kg ha-1 ${ }^{-1}$, Cuttack (194.3 kg ha $\left.{ }^{-1}\right)$, Jharsuguda (207.1 kg ha-1), Rayagada (221.6 kg ha-1), Jagatsinghpur (237.7 $\mathrm{kg} \mathrm{ha}^{-1}$ ), and Jajpur (271.2 $\mathrm{kg} \mathrm{ha}^{-1}$ ). Highest mean available $\mathrm{K}$ was observed adjacent to bauxite mining areas of Koraput (340.6 $\mathrm{kg} \mathrm{ha}^{-1}$ ) followed by iron mining areas of Keonjhar (320.4 $\left.\mathrm{kg} \mathrm{ha}^{-1}\right)$. The degraded soils of the present study were low to moderate in fertility status and mostly unsuitable for cultivation. 


\begin{tabular}{|c|c|c|c|c|c|c|c|c|}
\hline \multirow[t]{2}{*}{ Location and source of pollution } & \multirow[t]{2}{*}{ Block } & \multirow[t]{2}{*}{ District } & \multirow{2}{*}{$\begin{array}{c}\mathrm{pH} \\
(1: 2.5)\end{array}$} & \multirow{2}{*}{$\begin{array}{c}\text { EC (dS } \\
\left.\mathbf{m}^{-1}\right)\end{array}$} & \multirow{2}{*}{$\begin{array}{l}\text { Org. C } \\
(\%)\end{array}$} & \multicolumn{3}{|c|}{$\begin{array}{c}\text { Available nutrient (kg } \\
\text { ha-1) }^{-1} \text { ) }\end{array}$} \\
\hline & & & & & & $\mathbf{N}$ & $\mathbf{P}$ & $\mathbf{K}$ \\
\hline $\begin{array}{l}\text { 1. Malhar Hatting Tisco Tata (Tata Chro- } \\
\text { mium Factory) }\end{array}$ & Sukinda & Jajpur & 6.51 & 0.374 & 1.02 & 263.4 & 18.96 & 286.2 \\
\hline $\begin{array}{l}\text { 2. Kaliapani (Indian Metals and Ferro } \\
\text { Alloys Limited) }\end{array}$ & Sukinda & --do-- & 7.24 & 0.416 & 0.78 & 295.8 & 22.64 & 246.9 \\
\hline 3. Hatibari (Chromium mining areas) & Sukinda & --do-- & 7.51 & 0.639 & 0.94 & 318.3 & 36.68 & 280.4 \\
\hline 4. Palaskaa (Iron mines) & Joda & Keonjhar & 6.24 & 0.599 & 1.02 & 263.4 & 32.44 & 375.7 \\
\hline $\begin{array}{l}\text { 5. Baneikela (Essel mining and Indus- } \\
\text { tries Limited) }\end{array}$ & Joda & --do-- & 7.78 & 0.911 & 0.79 & 280.9 & 26.42 & 327.3 \\
\hline 6. Lohanda (Iron mines) & Joda & --do-- & 5.96 & 0.558 & 0.87 & 224.6 & 24.56 & 240.3 \\
\hline 7. Suakati (OMC Fe mines) & Banspal & --do-- & 6.06 & 0.572 & 1.88 & 265.9 & 38.64 & 374.4 \\
\hline 8. TolaJagar (Iron mines) & Banspal & --do-- & 5.89 & 0.663 & 0.63 & 250.9 & 9.72 & 284.3 \\
\hline $\begin{array}{l}\text { 9. Santhapada (Ash pond of NTPC } \\
\text { Limited) }\end{array}$ & Talcher & Angul & 5.75 & 0.172 & 0.69 & 238.9 & 13.68 & 166.4 \\
\hline $\begin{array}{l}\text { 10. Kudulau (Ash pond of NALCO Lim- } \\
\text { ited) }\end{array}$ & Talcher & --do-- & 7.85 & 0.914 & 1.12 & 305.9 & 32.64 & 279.2 \\
\hline 11. Bhogabereni (NTPC Limited) & Banarpal & --do-- & 6.91 & 0.237 & 0.35 & 238.3 & 8.78 & 123.5 \\
\hline 12. BitharBejaput (Bauxite mines) & Damonjodi & Koraput & 6.62 & 0.159 & 0.52 & 263.7 & 16.94 & 168.7 \\
\hline 13. Ambagaon (NALCO Refinery) & Damonjodi & --do-- & 6.12 & 0.258 & 1.22 & 275.7 & 28.74 & 512.5 \\
\hline $\begin{array}{l}\text { 14. Sukuabada (Utkal Alumina Interna- } \\
\text { tional Ltd.) }\end{array}$ & Rayagada & Rayagada & 6.17 & 0.143 & 0.34 & 265.7 & 6.27 & 203.4 \\
\hline $\begin{array}{l}\text { 15. Karlakona (Dumping yard of JK Paper } \\
\text { Mills) }\end{array}$ & Rayagada & --do-- & 6.76 & 0.234 & 0.51 & 258.2 & 22.69 & 261.2 \\
\hline $\begin{array}{l}\text { 16. Chanchandli (Dumping yard of JK } \\
\text { Paper Mills) }\end{array}$ & Rayagada & --do-- & 6.42 & 0.136 & 0.45 & 233.3 & 17.55 & 200.3 \\
\hline 17. Musadia, Paradeep (IFFCO Plant) & Kujang & Jagatsinghpur & 6.36 & 0.871 & 0.21 & 165.6 & 12.70 & 109.5 \\
\hline $\begin{array}{l}\text { 18. Baularia Palanda (Cargill India Pvt. } \\
\text { Ltd.) }\end{array}$ & Kujang & --do-- & 6.21 & 0.112 & 0.69 & 189.7 & 21.74 & 482.7 \\
\hline 19. Jhimani, Paradeep (Oil Refinery) & Kujang & --do-- & 4.47 & 0.109 & 0.15 & 133.4 & 10.78 & 85.8 \\
\hline $\begin{array}{l}\text { 20. PPL Township, Paradeep (Paradeep } \\
\text { Phosphate Ltd.) }\end{array}$ & Kujang & --do-- & 4.59 & 0.097 & 0.47 & 164.9 & 18.89 & 210.9 \\
\hline $\begin{array}{l}\text { 21. Atharbanki (Gypsum storage site of } \\
\text { IFFCO plant) }\end{array}$ & Kujang & --do-- & 5.51 & 0.088 & 1.08 & 229.7 & 60.12 & 242.8 \\
\hline 22. Udayabata (Goa Carbon Limited) & Kujang & --do-- & 5.37 & 0.092 & 0.63 & 224.3 & 20.38 & 294.2 \\
\hline $\begin{array}{l}\text { 23. Jhartarang (Kalunga Industrial } \\
\text { Estate) }\end{array}$ & Lathikata & Sundargarh & 6.74 & 0.153 & 0.99 & 156.5 & 28.89 & 315.1 \\
\hline 24. Marang Phiring (Sponge Iron Factory) & Lathikata & --do-- & 6.93 & 0.709 & 0.21 & 139.5 & 12.54 & 109.7 \\
\hline 25. Goibhanga (SLM Metal Industries) & Lathikata & --do-- & 5.94 & 0.574 & 0.24 & 182.9 & 9.18 & 103.2 \\
\hline $\begin{array}{l}\text { 26. San Brahmanitarang (Lotus Chemi- } \\
\text { cals Ltd.) }\end{array}$ & $\begin{array}{l}\text { Brahmanita- } \\
\text { rang }\end{array}$ & --do-- & 7.25 & 0.208 & 0.39 & 172.9 & 9.41 & 244.5 \\
\hline 27. Padmalaya Colony (Ferro Alloys) & Kuarmunda & --do-- & 6.97 & 0.837 & 0.46 & 145.7 & 15.85 & 221.3 \\
\hline $\begin{array}{l}\text { 28. Deogaon Colony (Rourkela Steel } \\
\text { plant) }\end{array}$ & Panposh & --do-- & 6.81 & 0.149 & 1.59 & 242.4 & 82.88 & 142.8 \\
\hline $\begin{array}{l}\text { 29. Sitalpada (Dumping yard, Rourkela } \\
\text { Steel Plant) }\end{array}$ & Panposh & --do-- & 7.25 & 0.125 & 0.32 & 208.7 & 19.84 & 114.1 \\
\hline 30. Ramabahal (Scan Steels Ltd.) & Rajgangpur & --do-- & 7.22 & 0.119 & 0.24 & 152.6 & 18.59 & 179.1 \\
\hline 31. Rajgangpur (OCL India Ltd.) & Rajgangpur & --do-- & 7.23 & 0.143 & 1.77 & 160.3 & 12.32 & 171.5 \\
\hline 32. Lamloi (M.R. Ferro Pvt. Ltd.) & Rajgangpur & --do-- & 6.75 & 0.291 & 0.75 & 159.3 & 41.44 & 128.6 \\
\hline
\end{tabular}


Assessment of Soil Microbes and Enzyme Activities in the Degraded Soils Adjacent to Industries and Mines and its Relation with Heavy Metal Contaminants

\begin{tabular}{|c|c|c|c|c|c|c|c|c|}
\hline 33. Kiripsira (Coal mines) & Hemgiri & --do-- & 6.79 & 0.211 & 1.74 & 112.6 & 45.38 & 232.1 \\
\hline 34. Kanika Hemgiri Road (ACB India Ltd.) & Hemgiri & --do-- & 6.63 & 0.145 & 0.58 & 149.5 & 8.81 & 293.7 \\
\hline $\begin{array}{l}\text { 35. Kurebaga (Ash pond, Vedanta Alu- } \\
\text { miniun Ltd.) }\end{array}$ & Jharsuguda & Jharsuguda & 6.56 & 0.121 & 0.53 & 126.9 & 5.82 & 173.3 \\
\hline 36. Kudopali (Samleswari Coal mines) & Jharsuguda & --do-- & 6.22 & 0.162 & 1.05 & 130.6 & 23.38 & 169.6 \\
\hline 37. Belpahar (Mahanadi Coal Fields Ltd.) & Lakhanpur & --do-- & 6.44 & 0.158 & 1.38 & 315.9 & 44.26 & 378.1 \\
\hline $\begin{array}{l}\text { 38. Ubuda (Global Coal and Mining Pvt. } \\
\text { Ltd.) }\end{array}$ & Lakhanpur & --do-- & 6.66 & 0.154 & 0.16 & 100.9 & 12.99 & 107.4 \\
\hline 39. Randia (Ferro Alloys Corporation) & Bhadrak & Bhadrak & 6.33 & 0.078 & 0.43 & 178.4 & 13.89 & 190.9 \\
\hline 40. Chengagadia (Chromite plant) & Bhadrak & --do-- & 6.49 & 0.134 & 0.69 & 151.5 & 21.52 & 187.6 \\
\hline 41. Khantapara (Biotechayur Pvt. Ltd.) & Bahanaga & Balasore & 6.77 & 0.122 & 0.45 & 170.6 & 13.44 & 127.2 \\
\hline $\begin{array}{l}\text { 42. Banparia (KarniThermoplast Pvt. } \\
\text { Ltd) }\end{array}$ & Remuna & --do-- & 6.39 & 0.151 & 0.44 & 146.3 & 22.40 & 196.9 \\
\hline 43. Khannagar (HariPlast) & $\begin{array}{l}\text { Balasore } \\
\text { Sadar }\end{array}$ & --do-- & 6.51 & 0.096 & 0.63 & 174.2 & 14.34 & 125.7 \\
\hline 44. Bampada (Birla Tyres) & Remuna & --do-- & 7.05 & 0.897 & 0.69 & 232.3 & 22.62 & 300.2 \\
\hline 45. Balagopalpur (Balasore Alloys Ltd) & Remuna & --do-- & 6.43 & 0.205 & 0.35 & 185.4 & 8.96 & 92.5 \\
\hline 46. Rathalpur (Emami Paper Mills Ltd) & Remuna & --do-- & 7.03 & 0.342 & 0.76 & 180.4 & 15.01 & 185.2 \\
\hline $\begin{array}{l}\text { 47. Hemachandrapur (Sri Mayur Biscuit } \\
\text { Co Pvt. Ltd) }\end{array}$ & Sarasakana & Mayurbhanj & 6.53 & 0.155 & 0.41 & 154.2 & 11.04 & 136.3 \\
\hline $\begin{array}{l}\text { 48. Pandarsil (Shiva Shakti Sponge Iron } \\
\text { Ltd) }\end{array}$ & Sukruli & --do-- & 6.51 & 0.189 & 0.62 & 216.5 & 11.65 & 150.8 \\
\hline 49. Jagaatpur (Cosboard Factory) & Jagatpur & Cuttack & 4.73 & 0.672 & 0.74 & 264.2 & 65.12 & 128.2 \\
\hline 50. Jagatpur (Pragati Milk Products Ltd.) & Jagatpur & --do-- & 5.03 & 1.067 & 0.20 & 193.3 & 89.53 & 132.5 \\
\hline $\begin{array}{l}\text { 51. Choudwar (Indian Metals and Ferro } \\
\text { Alloys Ltd.) }\end{array}$ & Jagatpur & --do-- & 5.41 & 1.268 & 0.85 & 372.0 & 90.46 & 289.2 \\
\hline $\begin{array}{l}\text { 52. Bainchua (Maa Durga Thermal Power } \\
\text { Company Ltd.) }\end{array}$ & Tangi & --do-- & 5.26 & 1.869 & 0.57 & 265.4 & 92.67 & 268.8 \\
\hline 53. Bhayatangi (RSB Castings Ltd.) & Tangi & --do-- & 5.67 & 0.725 & 0.65 & 305.2 & 74.89 & 152.7 \\
\hline $\begin{array}{l}\text { 54. Nuagam (Aska Cooperative Sugars } \\
\text { Ltd.) }\end{array}$ & Aska & Ganjam & 4.23 & 0.358 & 0.59 & 384.6 & 95.79 & 87.6 \\
\hline 55. Jayshree (Grasim Chemicals Ltd.) & Ganjam & --do-- & 7.04 & 0.763 & 0.46 & 272.8 & 56.52 & 145.3 \\
\hline Range & & & $\begin{array}{l}4.23- \\
7.85 \\
\end{array}$ & $\begin{array}{l}0.078- \\
1.869\end{array}$ & $\begin{array}{c}0.15- \\
1.88 \\
\end{array}$ & $\begin{array}{c}100.9- \\
384.6\end{array}$ & $\begin{array}{l}5.82- \\
95.79\end{array}$ & $\begin{array}{l}85.8- \\
512.5\end{array}$ \\
\hline Mean & & & 6.37 & 0.39 & 0.70 & 215.5 & 29.33 & 213.4 \\
\hline
\end{tabular}

Table 1: Physico-chemical properties in soils from mines and industrial areas.

Micronutrient contents in the soils from mines and industrial areas

The available Fe in the mines and adjacent to industrial areas ranged from 5.8 - $240.8 \mathrm{mg} \mathrm{kg}^{-1}$ with a mean value of $95.1 \mathrm{mg} \mathrm{kg}^{-1}$ (Table 2). Highest mean available Fe (208 $\left.\mathrm{mg} \mathrm{kg}^{-1}\right)$ was recorded in the soils of Ganjam district (208 $\mathrm{mg} \mathrm{kg}^{-1}$ ) followed by Jharsuguda (154.3 $\mathrm{mg} \mathrm{kg}^{-1}$ ) and Jagatsinghpur (132.6mg kg-1), however, the available Fe content in all the soils of the study area was found more than the critical limit of $4.0 \mathrm{mg} \mathrm{kg}^{-1}$ and around $67 \%$ soils contain $>50 \mathrm{mg} \mathrm{kg}^{-1}$ and $42 \%$ soils contain $>100 \mathrm{mg} \mathrm{kg}^{-1}$. The avail- able $\mathrm{Mn}$ in the soils ranged from 4.2 - $146.0 \mathrm{mg} \mathrm{kg}^{-1}$ ) with a mean value of $59.3 \mathrm{mg} \mathrm{kg}^{-1}$. Highest mean available $\mathrm{Mn}$ was observed in the soils of Ganjam (109.4 $\mathrm{mg} \mathrm{kg}^{-1}$ ) followed by Jharsuguda (91.3 $\mathrm{mg} \mathrm{kg}^{-1}$ ), Keonjhar (87.9 $\mathrm{mg} \mathrm{kg}^{-1}$ ) and Jajpur (85.1 $\mathrm{mg} \mathrm{kg}^{-1}$ ). It was noticed that more than $50 \%$ soils contain $>50 \mathrm{mg} \mathrm{kg}^{-1}$ and $18 \%$ soils contain $>100 \mathrm{mg} \mathrm{kg}^{-1}$ of available $\mathrm{Mn}$, All the soil samples contain available $\mathrm{Mn}$ beyond the critical limit of $2.0 \mathrm{mg} \mathrm{kg}^{-1}$. The available Fe is one of the most abundant elements in the composition of the earth material. It is mainly associated with atmospheric coarse particles, where it is normally accumulated in the neighborhood of emission sources [14]. 
Assessment of Soil Microbes and Enzyme Activities in the Degraded Soils Adjacent to Industries and Mines and its Relation with Heavy Metal Contaminants

\begin{tabular}{|c|c|c|c|c|c|c|c|c|c|}
\hline Location and source of pollution & Block & District & $\mathbf{F e}$ & $\mathbf{C u}$ & Mn & $\mathbf{Z n}$ & $\mathrm{Cr}$ & $\mathbf{N i}$ & $\mathbf{P b}$ \\
\hline $\begin{array}{l}\text { 1. Malhar Hatting Tisco Tata (Tata } \\
\text { Chromium Factory) }\end{array}$ & Sukinda & Jajpur & 145.9 & 0.24 & 129.2 & 1.16 & 178.37 & 3.08 & 11.25 \\
\hline $\begin{array}{l}\text { 2. Kaliapani (Indian Metals and Ferro } \\
\text { Alloys Limited) }\end{array}$ & Sukinda & --do-- & 117.2 & 0.32 & 82.6 & 1.57 & 135.24 & 12.84 & 9.38 \\
\hline 3. Hatibari (Chromium mining areas) & Sukinda & --do-- & 60.1 & 0.21 & 43.5 & 2.34 & 137.81 & 1.75 & 4.63 \\
\hline 4. Palaskaa (Iron mines) & Joda & Keonjhar & 160.2 & 0.25 & 132.5 & 1.48 & 79.53 & 0.78 & 9.54 \\
\hline $\begin{array}{l}\text { 5. Baneikela (Essel mining and Indus- } \\
\text { tries Limited) }\end{array}$ & Joda & --do-- & 115.2 & 0.54 & 95.7 & 1.21 & 40.27 & 0.71 & 7.07 \\
\hline 6. Lohanda (Iron mines) & Joda & --do-- & 91.1 & 0.57 & 79.6 & 2.58 & 45.42 & 1.35 & 7.17 \\
\hline 7. Suakati (OMC Fe mines) & Banspal & --do-- & 33.8 & 0.62 & 47.5 & 1.31 & 62.36 & 0.24 & 4.92 \\
\hline 8. Tolajagar (Iron mines) & Banspal & --do-- & 103.3 & 1.33 & 84.4 & 0.91 & 24.93 & 1.42 & 5.31 \\
\hline $\begin{array}{l}\text { 9. Santhapada (Ash pond of NTPC } \\
\text { Limited) }\end{array}$ & Talcher & Angul & 114.9 & 0.39 & 84.7 & 1.48 & 15.35 & 1.33 & 9.67 \\
\hline $\begin{array}{l}\text { 10. Kudulau (Ash pond of NALCO Lim- } \\
\text { ited) }\end{array}$ & Talcher & --do-- & 49.6 & 0.22 & 27.1 & 0.96 & 10.41 & 2.92 & 10.90 \\
\hline 11. Bhogabereni (NTPC Limited) & Banarpal & --do-- & 65.9 & 0.34 & 42.6 & 0.87 & 13.22 & 0.66 & 9.54 \\
\hline 12. BitharBejaput (Bauxite mines) & Damonjodi & Koraput & 105.2 & 2.23 & 25.7 & 0.72 & 8.94 & 0.26 & 18.92 \\
\hline 13. Ambagaon (NALCO Refinery) & Damonjodi & --do-- & 40.6 & 2.48 & 101.4 & 2.65 & 12.35 & 2.08 & 11.75 \\
\hline $\begin{array}{l}\text { 14. Sukuabada (Utkal Alumina Interna- } \\
\text { tional Ltd.) }\end{array}$ & Rayagada & Rayagada & 48.4 & 1.34 & 40.2 & 0.72 & 7.56 & 1.52 & 5.04 \\
\hline $\begin{array}{l}\text { 15. Karlakona (Dumping yard of JK } \\
\text { Paper Mills) }\end{array}$ & Rayagada & --do-- & 5.8 & 0.63 & 31.6 & 0.51 & 5.44 & 0.12 & 10.72 \\
\hline $\begin{array}{l}\text { 16. Chanchandli (Dumping yard of JK } \\
\text { Paper Mills) }\end{array}$ & Rayagada & --do-- & 56.6 & 3.40 & 69.4 & 1.61 & 15.27 & 0.95 & 8.97 \\
\hline 17. Musadia, Paradeep (IFFCO Plant) & Kujang & Jagatsinghpur & 17.4 & 1.21 & 18.8 & 0.95 & 6.85 & 0.48 & 4.84 \\
\hline $\begin{array}{l}\text { 18. Baularia Palanda (Cargill India Pvt. } \\
\text { Ltd.) }\end{array}$ & Kujang & --do-- & 84.5 & 3.22 & 54.8 & 2.13 & 32.18 & 1.48 & 12.26 \\
\hline 19. Jhimani, Paradeep (Oil Refinery) & Kujang & --do-- & 235.8 & 0.49 & 131.4 & 0.58 & 18.57 & 0.68 & 8.45 \\
\hline $\begin{array}{l}\text { 20. PPL Township, Paradeep (Paradeep } \\
\text { Phosphate Ltd.) }\end{array}$ & Kujang & --do-- & 197.4 & 5.46 & 11.6 & 1.45 & 21.69 & 1.65 & 9.16 \\
\hline $\begin{array}{l}\text { 21. Atharbanki (Gypsum storage site of } \\
\text { IFFCO plant) }\end{array}$ & Kujang & --do-- & 105.2 & 8.68 & 117.4 & 2.01 & 13.42 & 3.04 & 8.27 \\
\hline 22. Udayabata (Goa Carbon Limited) & Kujang & --do-- & 155.4 & 6.14 & 123.9 & 1.84 & 16.29 & 2.12 & 9.09 \\
\hline $\begin{array}{l}\text { 23. Jhartarang (Kalunga Industrial Es- } \\
\text { tate) }\end{array}$ & Lathikata & Sundargarh & 38.6 & 2.56 & 13.3 & 2.24 & 14.29 & 4.27 & 6.17 \\
\hline $\begin{array}{l}\text { 24. Marang Phiring (Sponge Iron Fac- } \\
\text { tory) }\end{array}$ & Lathikata & --do-- & 52.2 & 7.14 & 69.2 & 4.08 & 7.59 & 1.65 & 4.79 \\
\hline 25. Goibhanga (SLM Metal Industries) & Lathikata & --do-- & 216.4 & 2.83 & 143.7 & 2.17 & 20.37 & 6.44 & 11.84 \\
\hline $\begin{array}{l}\text { 26. San Brahmanitarang (Lotus Chemi- } \\
\text { cals Ltd.) }\end{array}$ & $\begin{array}{l}\text { Brahmanita- } \\
\text { rang }\end{array}$ & --do-- & 36.8 & 2.56 & 19.4 & 3.48 & 6.85 & 0.89 & 4.25 \\
\hline 27. Padmalaya Colony (Ferro Alloys) & Kuarmunda & --do-- & 20.3 & 3.92 & 21.5 & 4.16 & 4.79 & 0.49 & 3.19 \\
\hline $\begin{array}{l}\text { 28. Deogaon Colony (Rourkela Steel } \\
\text { plant) }\end{array}$ & Panposh & --do-- & 177.9 & 9.02 & 47.2 & 4.28 & 23.48 & 5.64 & 9.75 \\
\hline $\begin{array}{l}\text { 29. Sitalpada (Dumping yard, Rourkela } \\
\text { Steel Plant) }\end{array}$ & Panposh & --do-- & 42.6 & 2.41 & 6.9 & 6.36 & 6.09 & 1.08 & 5.12 \\
\hline 30. Ramabahal (Scan Steels Ltd.) & Rajgangpur & --do-- & 91.4 & 0.69 & 36.5 & 1.21 & 7.39 & 1.37 & 6.37 \\
\hline 31. Rajgangpur (OCL India Ltd.) & Rajgangpur & --do-- & 11.5 & 2.43 & 4.2 & 1.21 & 4.28 & 0.32 & 3.18 \\
\hline 32. Lamloi (M.R. Ferro Pvt. Ltd.) & Rajgangpur & --do-- & 42.4 & 3.69 & 32.6 & 2.09 & 5.37 & 0.45 & 4.69 \\
\hline 33. Kiripsira (Coal mines) & Hemgiri & --do-- & 31.3 & 7.78 & 89.6 & 6.12 & 4.85 & 0.29 & 3.56 \\
\hline $\begin{array}{l}\text { 34. Kanika Hemgiri Road (ACB India } \\
\text { Ltd.) }\end{array}$ & Hemgiri & --do-- & 50.9 & 2.92 & 100.8 & 2.44 & 5.16 & 0.62 & 4.22 \\
\hline $\begin{array}{l}\text { 35. Kurebaga (Ash pond, Vedanta Alu- } \\
\text { miniun Ltd.) }\end{array}$ & Jharsuguda & Jharsuguda & 33.6 & 1.31 & 60.8 & 1.72 & 3.89 & 0.19 & 3.67 \\
\hline
\end{tabular}


Assessment of Soil Microbes and Enzyme Activities in the Degraded Soils Adjacent to Industries and Mines and its Relation with Heavy Metal Contaminants

\begin{tabular}{|c|c|c|c|c|c|c|c|c|c|}
\hline 36. Kudopali (Samleswari Coal mines) & Jharsuguda & --do-- & 228.0 & 5.51 & 146.0 & 3.64 & 27.64 & 4.19 & 8.64 \\
\hline $\begin{array}{l}\text { 37. Belpahar (Mahanadi Coal Fields } \\
\text { Ltd.) }\end{array}$ & Lakhanpur & --do-- & 199.2 & 2.36 & 82.6 & 4.78 & 19.74 & 2.47 & 9.15 \\
\hline $\begin{array}{l}\text { 38. Ubuda (Global Coal and Mining Pvt. } \\
\text { Ltd.) }\end{array}$ & Lakhanpur & --do-- & 156.3 & 2.30 & 75.6 & 3.92 & 13.29 & 1.59 & 7.29 \\
\hline 39. Randia (Ferro Alloys Corporation) & Bhadrak & Bhadrak & 78.2 & 3.29 & 41.2 & 1.35 & 13.84 & 1.86 & 5.82 \\
\hline 40. Chengagadia (Chromite plant) & Bhadrak & --do-- & 151.6 & 3.43 & 12.7 & 1.28 & 11.76 & 2.05 & 5.16 \\
\hline 41. Khantapara (Biotechayur Pvt. Ltd.) & Bahanaga & Balasore & 45.6 & 2.17 & 17.4 & 0.52 & 2.98 & 2.54 & 11.71 \\
\hline $\begin{array}{l}\text { 42. Banparia (Karni Thermoplast Pvt. } \\
\text { Ltd) }\end{array}$ & Remuna & --do-- & 114.8 & 2.34 & 20.8 & 2.04 & 8.85 & 2.37 & 12.49 \\
\hline 43. Khannagar (HariPlast) & $\begin{array}{l}\text { Balasore } \\
\text { Sadar }\end{array}$ & --do-- & 103.8 & 2.06 & 61.5 & 5.42 & 29.48 & 1.21 & 11.54 \\
\hline 44. Bampada (Birla Tyres) & Remuna & --do-- & 73.6 & 5.40 & 16.1 & 1.27 & 3.99 & 0.79 & 12.68 \\
\hline 45. Balagopalpur (Balasore Alloys Ltd) & Remuna & --do-- & 93.2 & 2.27 & 37.2 & 5.44 & 6.75 & 0.98 & 12.68 \\
\hline 46. Rathalpur (Emami Paper Mills Ltd) & Remuna & --do-- & 46.5 & 3.83 & 31.5 & 2.12 & 3.99 & 0.88 & 6.08 \\
\hline $\begin{array}{l}\text { 47. Hemachandrapur (Sri Mayur Bis- } \\
\text { cuit Co Pvt. Ltd) }\end{array}$ & Sarasakana & Mayurbhanj & 70.3 & 1.86 & 32.8 & 2.28 & 2.52 & 0.32 & 9.68 \\
\hline $\begin{array}{l}\text { 48. Pandarsil (Shiva Shakti Sponge Iron } \\
\text { Ltd) }\end{array}$ & Sukruli & --do-- & 110.9 & 4.42 & 57.8 & 1.69 & 7.93 & 0.91 & 11.73 \\
\hline 49. Jagaatpur (Cosboard Factory) & Jagatpur & Cuttack & 122.8 & 6.64 & 61.5 & 1.85 & 3.65 & 0.35 & 5.21 \\
\hline $\begin{array}{l}\text { 50. Jagatpur (Pragati Milk Products } \\
\text { Ltd.) }\end{array}$ & Jagatpur & --do-- & 76.8 & 2.76 & 7.2 & 1.08 & 4.08 & 0.51 & 10.29 \\
\hline $\begin{array}{l}\text { 51. Choudwar (Indian Metals and Ferro } \\
\text { Alloys Ltd.) }\end{array}$ & Jagatpur & --do-- & 46.7 & 7.83 & 20.8 & 2.46 & 9.92 & 1.21 & 12.48 \\
\hline $\begin{array}{l}\text { 52. Bainchua (Maa Durga Thermal } \\
\text { Power Company Ltd.) }\end{array}$ & Tangi & --do-- & 85.5 & 4.51 & 50.3 & 1.28 & 6.36 & 1.95 & 9.58 \\
\hline 53. Bhayatangi (RSB Castings Ltd.) & Tangi & --do-- & 52.0 & 3.76 & 23.2 & 0.61 & 4.76 & 0.95 & 6.34 \\
\hline $\begin{array}{l}\text { 54. Nuagam (Aska Cooperative Sugars } \\
\text { Ltd.) }\end{array}$ & Aska & Ganjam & 240.8 & 5.22 & 126.8 & 1.47 & 7.29 & 1.20 & 4.21 \\
\hline 55. Jayshree (Grasim Chemicals Ltd.) & Ganjam & --do-- & 176.1 & 5.34 & 91.9 & 1.35 & 15.36 & 5.68 & 18.42 \\
\hline Range & & & $\begin{array}{c}5.8- \\
240.8\end{array}$ & $\begin{array}{l}0.21- \\
9.02\end{array}$ & $\begin{array}{c}4.2- \\
146.0\end{array}$ & $\begin{array}{l}0.51- \\
6.36\end{array}$ & $\begin{array}{c}2.52- \\
178.37\end{array}$ & $\begin{array}{l}0.12- \\
12.84\end{array}$ & $\begin{array}{l}3.18- \\
18.92\end{array}$ \\
\hline
\end{tabular}

Table 2: Heavy metal contents $\left(\mathrm{mg} \mathrm{kg}^{-1}\right)$ in the soils from mines and industrial areas of Odisha.

All the soils from these polluted areas have recorded higher than the critical limits of 0.60 and $0.20 \mathrm{mg} \mathrm{kg}^{-1}$ of available $\mathrm{Zn}$ and $\mathrm{Cu}$, respectively. The available $\mathrm{Zn}$ in the soils of the present study ranged from $0.51-6.36 \mathrm{mg} \mathrm{kg}^{-1}$ with a mean value of $2.15 \mathrm{mg} \mathrm{kg}$ ${ }^{1}$. Highest mean available $\mathrm{Zn}$ was found in the soils of Jharsuguda ( $3.52 \mathrm{mg} \mathrm{kg}^{-1}$ ) followed by Sundargarh ( $3.32 \mathrm{mg} \mathrm{kg}^{-1}$ ) and Balasore ( $2.80 \mathrm{mg} \mathrm{kg}^{-1}$ ). The available $\mathrm{Cu}$ in the soils varied from $0.21-9.02$ $\mathrm{mg} \mathrm{kg}{ }^{-1}$ with a mean value of $3.03 \mathrm{mg} \mathrm{kg}^{-1}$. Highest mean available $\mathrm{Cu}$ was observed in these polluted soils of Ganjam (5.28 mg kg${ }^{-1}$ ) followed by Cuttack ( $5.10 \mathrm{mg} \mathrm{kg}^{-1}$ ), Jagatsinghpur (4.20 $\left.\mathrm{mg} \mathrm{kg}^{-1}\right)$, Sundargarh (3.99 $\mathrm{mg} \mathrm{kg}^{-1}$ ) and Jharsuguda (2.87 $\mathrm{mg} \mathrm{kg}^{-1}$ ).

The DTPA extractable $\mathrm{Cr}$ in the polluted soils ranged from 2.52 - $178.37 \mathrm{mg} \mathrm{kg}^{-1}$. Highest $\mathrm{Cr}$ values (Figure 1) were observed in the mining areas of Jajpur district (ranged from 135.2 - $178.4 \mathrm{mg} \mathrm{kg}^{-1}$, with a mean of $150.5 \mathrm{mg} \mathrm{kg}^{-1}$ ) followed by Keonjhar (ranged from $24.9-79.5 \mathrm{mg} \mathrm{kg}^{-1}$, with a mean of $50.5 \mathrm{mg} \mathrm{kg}^{-1}$ ). The soils also contain 3.18 - 18.92 of $\mathrm{Pb}$ (mean $8.34 \mathrm{mg} \mathrm{kg}^{-1}$ ) (Figure 2) and 0.12 - $12.84 \mathrm{mg} \mathrm{kg}^{-1}$ of Ni (mean $1.80 \mathrm{mg} \mathrm{kg}^{-1}$ ) (Figure 3). Thus, it was observed that Sukinda block of Jajpur district contain very high levels of $\mathrm{Cr}, \mathrm{Ni}$, and $\mathrm{Fe}$, bauxite mining areas of Koraput and industrial areas of Ganjam contain high levels of $\mathrm{Pb}$, industrial areas of Sundargarh contain high levels of Zn, iron mining areas of Keonjhar contain toxic levels of $\mathrm{Mn}$ and Fe and these heavy metals through soil - plant - animal ecosystem causing numerous hazards to crops, livestock and human beings. 


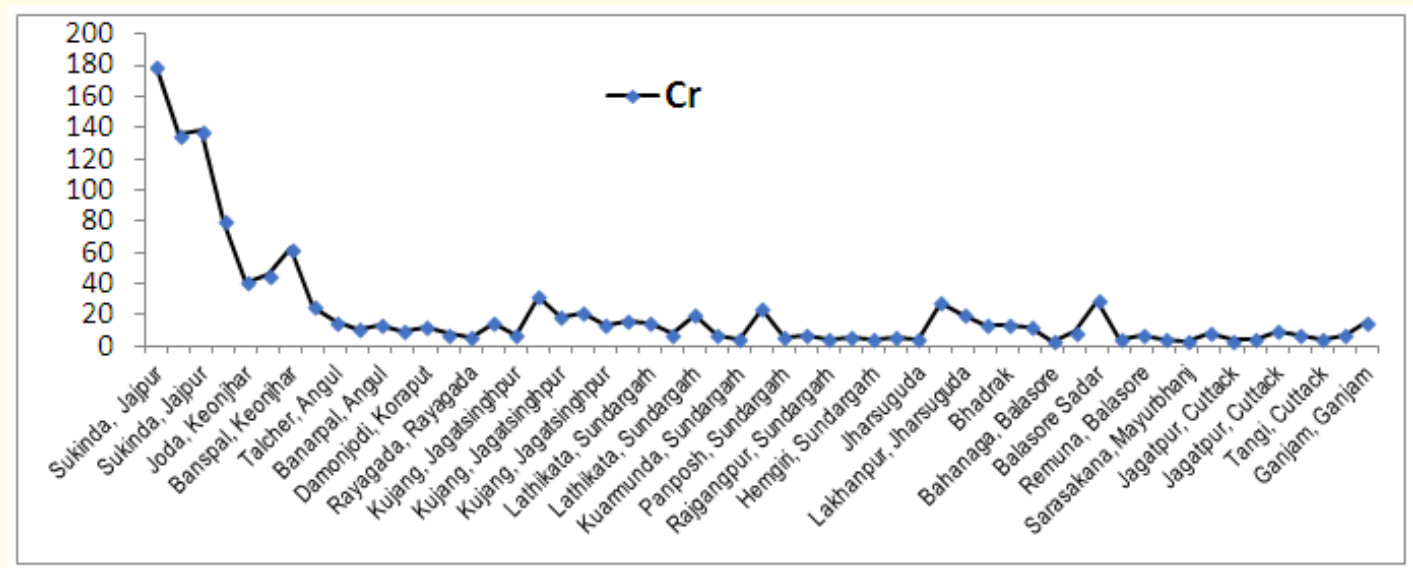

Figure 1: Accumulation of chromium in the soils adjacent to mining and industrial areas of Odisha.

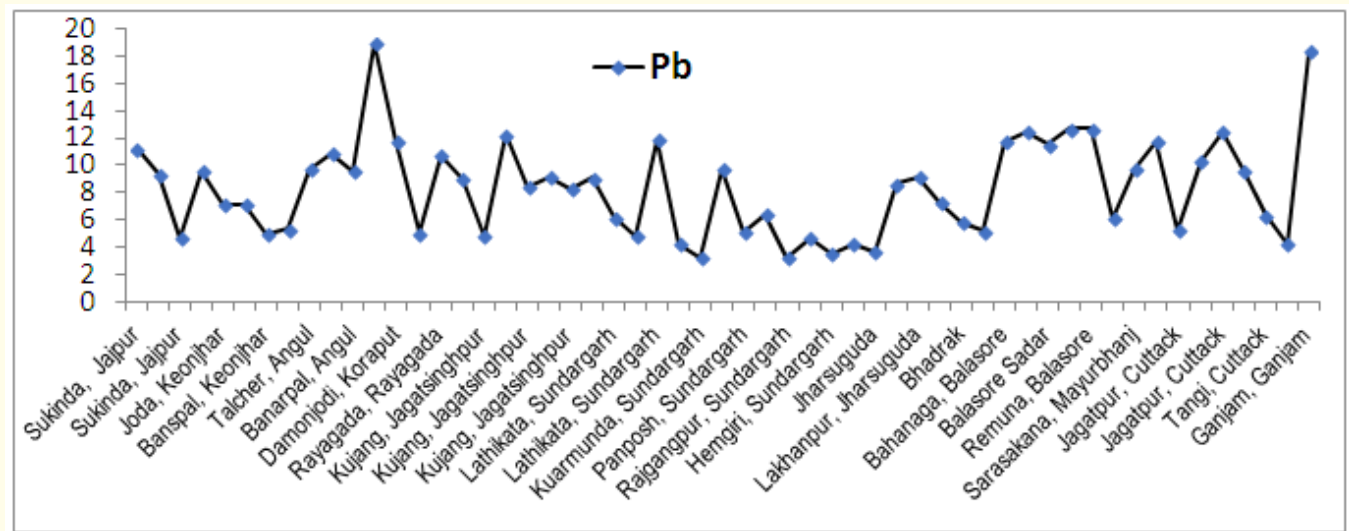

Figure 2: Accumulation of lead in the soils adjacent to mining and industrial areas of Odisha.

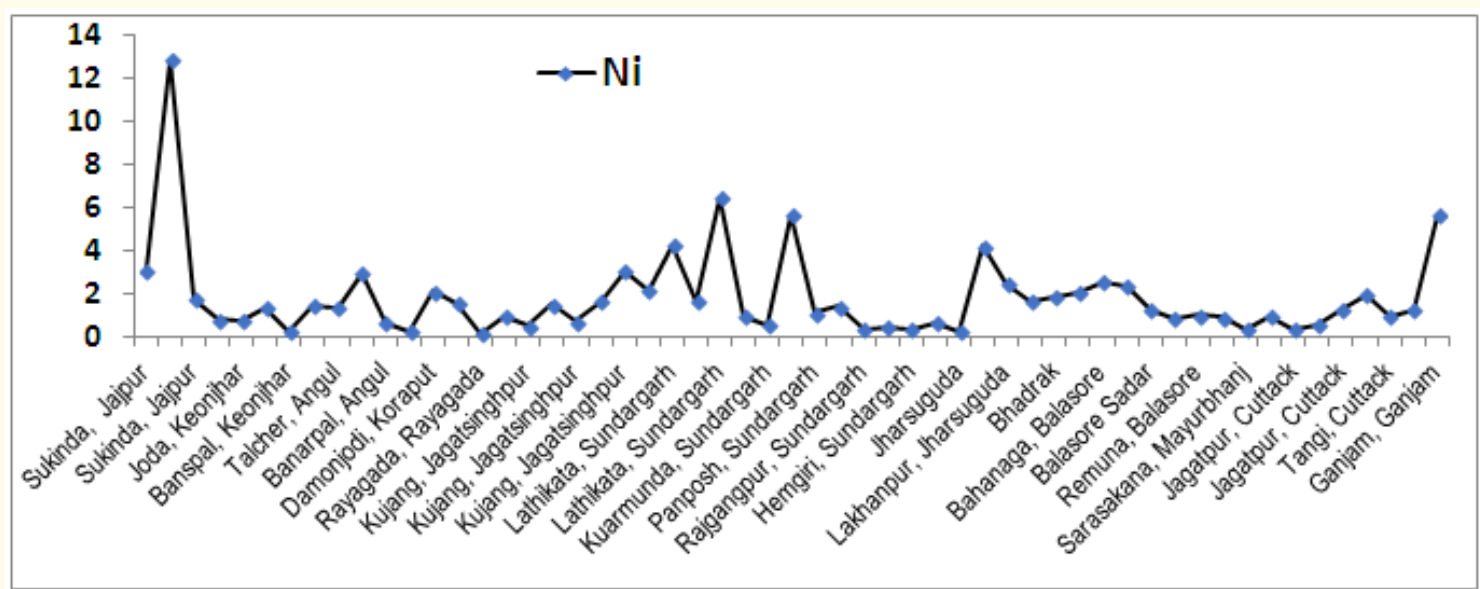

Figure 3: Accumulation of nickel in the soils adjacent to mining and industrial areas of Odisha. 
Assessment of Soil Microbes and Enzyme Activities in the Degraded Soils Adjacent to Industries and Mines and its Relation with Heavy Metal Contaminants

Microbial diversity and biological activities in the soils from mining and industrial areas

Highest microbial counts (Table 3) were recorded in the soils of bauxite mining areas of Koraput district followed by Keonjhar, Jajpur and Rayagada. Highest fungal counts $\left(47 \times 10^{4} \mathrm{cfu} \mathrm{g}^{-1}\right)$ were observed in the iron mining areas of Keonjhar, whereas highest bacterial counts $\left(54 \times 10^{5} \mathrm{cfu} \mathrm{g}^{-1}\right)$ and actinomycetes $\left(54 \times 10^{4} \mathrm{cfu}\right.$ $\mathrm{g}^{-1}$ ) were noticed in the soils adjacent to paper mill of Rayagada and coal mining areas of Sundargarh districts, respectively. Lowest microbial counts were observed in the soils adjacent to industrial areas of Cuttack and Ganjam districts.

\begin{tabular}{|c|c|c|c|c|c|c|c|}
\hline \multirow[b]{2}{*}{ Location and source of pollution } & \multicolumn{3}{|c|}{ Total microbial counts } & \multicolumn{4}{|c|}{ Soil enzyme activities } \\
\hline & $\begin{array}{l}\text { Fungi } \\
\left(1 \times 10^{4}\right. \\
\left.\text { cfu. } g^{-1}\right)\end{array}$ & $\begin{array}{c}\text { Bacteria } \\
\left(1 \times 10^{5}\right. \\
\left.\text { cfu g }^{-1}\right)\end{array}$ & $\begin{array}{c}\text { Actinomy- } \\
\text { cetes } \\
\left(1 \times 10^{4}\right. \\
\left.\text { cfu.g }^{-1}\right)\end{array}$ & $\begin{array}{c}\text { DHA } \\
\text { ( } \mu \mathrm{g} \text { TPF } \\
\left.\mathrm{hr}^{-1} \mathrm{~g}^{-1}\right)\end{array}$ & $\begin{array}{c}\text { FDA } \\
\left(\mu g^{-1}\right. \\
\left.\mathbf{h r}^{-1}\right)\end{array}$ & $\begin{array}{l}\text { Acid Phos- } \\
\text { phatase }(\mu \mathrm{g} \\
\left.\text { PNP g }^{-1} \mathbf{h r}^{-1}\right)\end{array}$ & $\begin{array}{c}\text { Alkaline } \\
\text { Phospha- } \\
\text { tase } \\
\text { ( } \mu \text { g PNP g-1 } \\
\text { hr-1) }^{-1}\end{array}$ \\
\hline $\begin{array}{l}\text { 1. Malhar Hatting Tisco Tata (Chromium } \\
\text { mines) }\end{array}$ & 39 & 30 & 32 & 2.183 & 2.475 & 69.96 & 31.83 \\
\hline $\begin{array}{l}\text { 2. Kaliapani (Indian Metals and Ferro } \\
\text { Alloys Limited) }\end{array}$ & 32 & 37 & 25 & 2.457 & 2.511 & 65.91 & 29.88 \\
\hline 3. Hatibari (Chromium mining areas) & 38 & 34 & 27 & 2.356 & 2.522 & 70.14 & 33.1 \\
\hline 4. Palaskaa (Iron mines) & 43 & 45 & 39 & 2.502 & 2.656 & 60.17 & 27.08 \\
\hline $\begin{array}{l}\text { 5. Baneikela (Essel mining and Indus- } \\
\text { tries Limited) }\end{array}$ & 30 & 36 & 32 & 2.265 & 2.458 & 75.38 & 36.1 \\
\hline 6. Lohanda (Iron mines) & 35 & 48 & 23 & 1.591 & 1.601 & 31.08 & 23.21 \\
\hline 7. Suakati (OMC Fe mines) & 47 & 35 & 46 & 2.506 & 2.707 & 22.95 & 18.87 \\
\hline 8. TolaJagar (Iron mines) & 27 & 45 & 22 & 0.741 & 0.884 & 22.71 & 15.04 \\
\hline $\begin{array}{l}\text { 9. Santhapada (Ash pond of NTPC } \\
\text { Limited) }\end{array}$ & 26 & 31 & 24 & 0.686 & 0.882 & 46.79 & 28.35 \\
\hline $\begin{array}{l}\text { 10. Kudulau (Ash pond of NALCO Lim- } \\
\text { ited) }\end{array}$ & 36 & 36 & 31 & 2.046 & 1.456 & 53.63 & 37.34 \\
\hline 11. Bhogabereni (NTPC Limited) & 29 & 34 & 18 & 0.733 & 1.338 & 56.78 & 26.21 \\
\hline 12. BitharBejaput (Bauxite mines) & 36 & 52 & 29 & 0.918 & 0.622 & 24.56 & 26.04 \\
\hline 13. Ambagaon (NALCO Refinery) & 45 & 47 & 51 & 2.031 & 1.639 & 64.03 & 49.87 \\
\hline $\begin{array}{l}\text { 14. Sukuabada (Utkal Alumina Interna- } \\
\text { tional Ltd.) }\end{array}$ & 36 & 31 & 24 & 0.728 & 0.523 & 6.12 & 11.17 \\
\hline $\begin{array}{l}\text { 15. Karlakona (Dumping yard of JK Paper } \\
\text { Mills) }\end{array}$ & 46 & 54 & 32 & 1.629 & 1.726 & 11.55 & 16.08 \\
\hline $\begin{array}{l}\text { 16. Chanchandli (Dumping yard of JK } \\
\text { Paper Mills) }\end{array}$ & 24 & 25 & 28 & 0.483 & 0.244 & 13.9 & 19.07 \\
\hline 17. Musadia, Paradeep (IFFCO Plant) & 21 & 23 & 22 & 0.186 & 0.152 & 13.48 & 15.83 \\
\hline $\begin{array}{l}\text { 18. Baularia Palanda (Cargill India Pvt. } \\
\text { Ltd.) }\end{array}$ & 24 & 27 & 31 & 0.311 & 0.302 & 22.08 & 23.44 \\
\hline 19. Jhimani, Paradeep (Oil Refinery) & 19 & 20 & 14 & 0.291 & 0.226 & 16.07 & 9.68 \\
\hline $\begin{array}{l}\text { 20. PPL Township, Paradeep (Paradeep } \\
\text { Phosphate Ltd.) }\end{array}$ & 28 & 33 & 27 & 0.596 & 0.221 & 21.24 & 22.27 \\
\hline $\begin{array}{l}\text { 21. Atharbanki (Gypsum storage site of } \\
\text { IFFCO plant) }\end{array}$ & 39 & 35 & 42 & 0.728 & 0.523 & 19.12 & 17.17 \\
\hline 22. Udayabata (Goa Carbon Limited) & 27 & 41 & 29 & 0.629 & 0.726 & 11.55 & 16.08 \\
\hline $\begin{array}{l}\text { 23. Jhartarang (Kalunga Industrial } \\
\text { Estate) }\end{array}$ & 24 & 22 & 33 & 1.256 & 0.665 & 38.54 & 40.72 \\
\hline 24. Marang Phiring (Sponge Iron Factory) & 21 & 26 & 22 & 1.059 & 0.517 & 16.14 & 14.76 \\
\hline 25. Goibhanga (SLM Metal Industries) & 24 & 29 & 27 & 1.224 & 0.523 & 22.25 & 25.66 \\
\hline
\end{tabular}


Assessment of Soil Microbes and Enzyme Activities in the Degraded Soils Adjacent to Industries and Mines and its Relation with Heavy Metal Contaminants

\begin{tabular}{|c|c|c|c|c|c|c|c|}
\hline $\begin{array}{l}\text { 26. San Brahmanitarang (Lotus Chemi- } \\
\text { cals Ltd.) }\end{array}$ & 27 & 27 & 29 & 1.504 & 1.024 & 16.29 & 24.35 \\
\hline 27. Padmalaya Colony (Ferro Alloys) & 29 & 19 & 23 & 1.124 & 0.646 & 46.38 & 30.56 \\
\hline $\begin{array}{l}\text { 28. Deogaon Colony (Rourkela Steel } \\
\text { plant) }\end{array}$ & 44 & 36 & 46 & 1.866 & 1.631 & 49.72 & 35.49 \\
\hline $\begin{array}{l}\text { 29. Sitalpada (Dumping yard, Rourkela } \\
\text { Steel Plant) }\end{array}$ & 23 & 30 & 35 & 1.085 & 0.297 & 27.83 & 25.62 \\
\hline 30. Ramabahal (Scan Steels Ltd.) & 21 & 23 & 29 & 1.189 & 0.652 & 28.45 & 29.17 \\
\hline 31. Rajgangpur (OCL India Ltd.) & 46 & 34 & 35 & 2.671 & 1.256 & 18.15 & 17.08 \\
\hline 32. Lamloi (M.R. Ferro Pvt. Ltd.) & 31 & 26 & 29 & 1.672 & 1.552 & 39.69 & 32.56 \\
\hline 33. Kiripsira (Coal mines) & 38 & 46 & 54 & 1.081 & 0.638 & 24.78 & 25.19 \\
\hline 34. KanikaHemgiri Road (ACB India Ltd.) & 25 & 29 & 32 & 1.214 & 0.224 & 13.36 & 17.97 \\
\hline $\begin{array}{l}\text { 35. Kurebaga (Ash pond, Vedanta Alu- } \\
\text { miniun Ltd.) }\end{array}$ & 24 & 23 & 26 & 1.288 & 1.319 & 12.39 & 14.59 \\
\hline 36. Kudopali (Samleswari Coal mines) & 28 & 18 & 21 & 1.788 & 1.019 & 12.66 & 19.86 \\
\hline 37. Belpahar (Mahanadi Coal Fields Ltd.) & 37 & 45 & 42 & 1.849 & 1.862 & 57.84 & 43.12 \\
\hline $\begin{array}{l}\text { 38. Ubuda (Global Coal and Mining Pvt. } \\
\text { Ltd.) }\end{array}$ & 19 & 17 & 17 & 1.281 & 1.049 & 16.94 & 15.62 \\
\hline 39. Randia (Ferro Alloys Corporation) & 22 & 45 & 35 & 1.017 & 0.525 & 28.19 & 21.64 \\
\hline 40. Chengagadia (Chromite plant) & 31 & 28 & 34 & 1.669 & 1.283 & 16.34 & 20.81 \\
\hline 41. Khantapara (Biotechayur Pvt. Ltd.) & 19 & 22 & 28 & 1.392 & 1.054 & 12.17 & 19.12 \\
\hline $\begin{array}{l}\text { 42. Banparia (KarniThermoplast Pvt. } \\
\text { Ltd) }\end{array}$ & 21 & 33 & 26 & 1.429 & 1.296 & 26.62 & 22.54 \\
\hline 43. Khannagar (HariPlast) & 33 & 28 & 29 & 1.479 & 1.365 & 12.26 & 18.75 \\
\hline 44. Bampada (Birla Tyres) & 35 & 47 & 35 & 1.605 & 0.888 & 36.48 & 31.79 \\
\hline 45. Balagopalpur (Balasore Alloys Ltd) & 22 & 21 & 36 & 1.364 & 1.424 & 12.38 & 20.95 \\
\hline 46. Rathalpur (Emami Paper Mills Ltd) & 38 & 33 & 45 & 1.712 & 1.165 & 21.38 & 21.78 \\
\hline $\begin{array}{l}\text { 47. Hemachandrapur (Sri Mayur Biscuit } \\
\text { Co Pvt. Ltd) }\end{array}$ & 21 & 22 & 23 & 1.393 & 1.543 & 11.88 & 18.38 \\
\hline $\begin{array}{l}\text { 48. Pandarsil (Shiva Shakti Sponge Iron } \\
\text { Ltd) }\end{array}$ & 26 & 32 & 29 & 1.595 & 2.058 & 12.77 & 18.94 \\
\hline 49. Jagaatpur (Cosboard Factory) & 19 & 23 & 17 & 0.436 & 0.703 & 16.26 & 12.59 \\
\hline 50. Jagatpur (Pragati Milk Products Ltd.) & 22 & 31 & 25 & 0.485 & 0.596 & 18.59 & 16.35 \\
\hline $\begin{array}{l}\text { 51. Choudwar (Indian Metals and Ferro } \\
\text { Alloys Ltd.) }\end{array}$ & 15 & 27 & 23 & 0.716 & 1.048 & 15.84 & 17.85 \\
\hline $\begin{array}{l}\text { 52. Bainchua (Maa Durga Thermal Power } \\
\text { Company Ltd.) }\end{array}$ & 17 & 24 & 25 & 0.695 & 0.569 & 21.30 & 17.47 \\
\hline 53. Bhayatangi (RSB Castings Ltd.) & 20 & 26 & 27 & 0.357 & 0.548 & 18.87 & 20.31 \\
\hline $\begin{array}{l}\text { 54. Nuagam (Aska Cooperative Sugars } \\
\text { Ltd.) }\end{array}$ & 18 & 27 & 16 & 0.758 & 1.124 & 21.25 & 16.52 \\
\hline 55. Jayshree (Grasim Chemicals Ltd.) & 14 & 19 & 18 & 0.638 & 0.836 & 15.34 & 17.95 \\
\hline Range & $14-47$ & $17-54$ & $14-54$ & $\begin{array}{l}0.186- \\
2.671\end{array}$ & $\begin{array}{l}0.152- \\
2.707\end{array}$ & $6.12-75.38$ & $9.68-49.87$ \\
\hline Mean & 28.7 & 31.6 & 29.4 & 1.282 & 1.114 & 28.34 & 23.27 \\
\hline
\end{tabular}

Table 3: Microbial counts and enzyme activities in soils from mines and industrial areas. 
Assessment of Soil Microbes and Enzyme Activities in the Degraded Soils Adjacent to Industries and Mines and its Relation with Heavy Metal Contaminants

Dehydrogenase activity is a measure of microbial metabolism and thus of the oxidative microbial activity of soils and dehydrogenases are involved in the oxidation and energy transfer of microbial cells. Highest dehydrogenase activity (Table 3 ) was noticed in the soils of Jajpur district (ranged from $2.183-2.457 \mu \mathrm{g}$ TPF $\mathrm{hr}^{-1} \mathrm{~g}^{-1}$, mean $2.332 \mu \mathrm{g}$ TPF $\mathrm{hr}^{-1} \mathrm{~g}^{-1}$ ) followed by Keonjhar (mean $1.921 \mu \mathrm{g}$ $\mathrm{TPF} \mathrm{hr} \mathrm{g}^{-1}$ ). Fluorescein Diacetate Hydrolysis Assay is often used as an indicator of microbial activity and is correlated with microbial respiration [15]. As such it is a simple, non-specific, but sensitive technique that can be used to estimate relative levels of microbial activity in soils, and has been recommended as a useful parameter to assess soil quality [16]. In line with the dehydrogenase activity, highest Fluorescein Diacetate Activity (ranged from 2.475- 2.522 $\mu \mathrm{g} \mathrm{g}^{-1} \mathrm{hr}^{-1}$, mean $2.508 \mu \mathrm{g} \mathrm{g}^{-1} \mathrm{hr}^{-1}$ ) was observed in the Cr mining areas of Jajpur district followed by iron mining areas of Keonjhar district (mean $2.062 \mu \mathrm{g} \mathrm{g}^{-1} \mathrm{hr}^{-1}$ ). Lowest biological activities in terms of DHA and FDA were observed in the soils contaminated with industries of Cuttack, Ganjam, Jagatsinghpur and Jharsuguda districts of Odisha. Higher activities of dehydrogenase and fluorescein diacetate in these polluted soils, which may be ascribed to greater availability of substrates that support such activities as well as the cofactors of several enzymes, were highly influenced by supplementing of micronutrients [17].
An increasing trend of acid phosphatase was observed in all the soil samples collected from polluted areas of Odisha over that of alkaline phosphatase. Highest acid phosphatase activities (Table 3) were observed in the soils contaminated with $\mathrm{Cr}$ mining activities at Sukinda block of Jajpur district (mean of $68.67 \mu \mathrm{g} \mathrm{PNP} \mathrm{g}^{-1} \mathrm{hr}^{-1}$ ) followed by bauxite mining areas of Koraput (44.30 $\mu \mathrm{g}$ PNP g-1 $\mathrm{hr}^{-}$ ${ }^{1}$ ), while the lowest acid phosphatase activities were noticed in the soils. Highest mean alkaline phosphatase activities were recorded in the soils of Koraput district (37.96 $\mu \mathrm{g} \mathrm{PNP} \mathrm{g}^{-1} \mathrm{hr}^{-1}$ ) followed by Sundargarh (26.59 $\mu \mathrm{g}$ PNP $\mathrm{g}^{-1} \mathrm{hr}^{-1}$ ). Both acid and alkaline phosphatase activities were found lowest in the polluted soils of Cuttack, Ganjam and Rayagada districts. The activities of both alkaline and acid phosphatases were closely related to soil $\mathrm{pH}$, parent material and other soil forming factors [18].

\section{Relationship between soil microbes and enzyme activities}

Perusal of the data in table 4 revealed that the fungi had significantly higher relationship with dehydrogenase activity $\left(r=0.599^{* *}\right)$ and FDA $\left(r=0.529^{* *}\right)$. It was noticed that among the soil microflora only fungi had significant relationship with acid phosphatase $(\mathrm{r}=$ $\left.382^{*}\right)$ and alkaline phosphatase ( $\left.r=0.332^{*}\right)$, whereas actinomycetes had significant relationship with alkaline phosphatase $(\mathrm{r}=$ $\left.0.429^{*}\right)$. The results indicated that fungi and actinomycetes significantly influenced the soil enzymes, which in turn involved in biochemical transformation of nutrients in the soil.

\begin{tabular}{|l|c|c|c|c|}
\hline Soil microbes & DHA & FDA & Acid Phosphatase & Alkaline Phosphatase \\
\hline Fungi & $0.667^{* *}$ & $0.534^{* *}$ & $0.427^{*}$ & $0.412^{*}$ \\
\hline Bacteria & $0.307^{*}$ & 0.300 & $0.341^{*}$ & $0.318^{*}$ \\
\hline Actinomycetes & $0.467^{* *}$ & 0.269 & 0.262 & $0.487^{* *}$ \\
\hline
\end{tabular}

Table 4: Relationship (r) between soil microbes and enzymes activities. *and ${ }^{* *}$ Significant at 5.0 and 1.0 per cent level, respectively.

Relationship between soil properties and microbial variables

The soil $\mathrm{pH}$ had significant relationship with dehydrogenase activity $\left(r=0.510^{* *}\right)$, FDA $(r=0.331)$, acid phosphatase $\left(r=0.349^{*}\right)$ and alkaline phosphatase $\left(r=0.380^{*}\right.$ ) (Table 5). Variations in soil reaction had no effect on multiplication of soil microbes, but it had positive effect on enzyme activities in the soil. The changes in microbial biomass and microbial activity were related to the variations in $\mathrm{pH}$, which induce the development of bacteria to the detriment of fungi, and to the nutrient levels after addition of various organic amendments [19]. 
Assessment of Soil Microbes and Enzyme Activities in the Degraded Soils Adjacent to Industries and Mines and its Relation with Heavy Metal Contaminants

\begin{tabular}{|l|c|c|c|c|c|c|c|}
\hline Soil properties & Fungi & Bacteria & Actinomycetes & DHA & FDA & Acid phosphatase & Alkaline phosphatase \\
\hline pH & $0.310^{*}$ & 0.097 & 0.291 & $0.568^{* *}$ & $0.340^{*}$ & $0.363^{*}$ & $0.445^{* *}$ \\
\hline EC & -0.195 & -0.050 & -0.207 & -0.075 & 0.043 & 0.151 & -0.010 \\
\hline Org. C & $0.696^{* *}$ & $0.387^{*}$ & $0.666^{* *}$ & $0.574^{* *}$ & $0.474^{* *}$ & $0.364^{*}$ & $0.406^{*}$ \\
\hline Available N & 0.170 & $0.348^{*}$ & 0.005 & 0.096 & $0.375^{*}$ & $0.395^{*}$ & 0.231 \\
\hline Available P & -0.113 & -0.025 & 0.037 & -0.171 & 0.014 & 0.054 & 0.018 \\
\hline Available K & $0.459^{* *}$ & $0.469^{* *}$ & $0.494^{* *}$ & $0.334^{*}$ & $0.322^{*}$ & $0.444^{* *}$ & $0.499^{* *}$ \\
\hline
\end{tabular}

Table 5: Relationship (r) between soil chemical properties and microbial variables.

"and" Significant at 5.0 and 1.0 per cent level, respectively.

The organic carbon showed highly significant relationship with soil fungi $\left(r=0.763^{* *}\right)$ followed by actinomycetes $\left(r=0.701^{* *}\right)$ and fungi $\left(r=0.389^{\circ}\right)$. It was also noticed that dehydrogenase activity, fluorescein diacetate assay, acid phosphatase and alkaline phosphatase had significant relationship with soil organic $\mathrm{C}$ and the ' $r$ ' values were found to be $0.593^{* *}, 0.466^{*}, 0.359^{*}$ and $0.402^{*}$, respectively). Organic matter is the store house of various groups of microbes and hence improvement in organic matter had significant role in accumulation of micro-flora and various groups of enzymes involved in different bio-chemical processes in the soil. Soil phosphatase activity was closely related to soil organic matter content, supporting previous reports that elevated organic matter levels promote soil phosphatase activity [20].

The salt content of the soil had non-significant relationship with microbes and biological activities. Significant relationship was observed between soil fungi and available $\mathrm{N}, \mathrm{P}$ and $\mathrm{K}\left(\mathrm{r}=0.567^{* *}\right.$, $0.549^{* *}$ and $0.474^{* *}$, respectively), however, available $\mathrm{P}$ showed highly significant relationship with actinomycetes $\left(r=0.601^{* *}\right)$ and available $\mathrm{K}$ had significant relationship with bacteria $\left(\mathrm{r}=0.474^{* *}\right)$, indicated that soil bacteria were mostly involved in the transformation of $\mathrm{N}, \mathrm{P}$ and $\mathrm{K}$ in comparison to other microbes in the heavy metal contaminated soils of Odisha. Dehydrogenase Activity had significant relationship with available $\mathrm{N}$ and $\mathrm{P}\left(\mathrm{r}=0.367^{*}\right.$ and $0.313^{*}$, respectively), whereas FDA showed significant relationship with available $\mathrm{N}$ and $\mathrm{K}\left(\mathrm{r}=0.539^{* *}\right.$ and $0.314^{*}$, respectively). Both dehydrogenase and FDA had significant relationship with available $\mathrm{N}, \mathrm{P}$ and $\mathrm{K}$, indicated that these two enzymes are involved in the transformations of $\mathrm{N}, \mathrm{P}$ and $\mathrm{K}$. Alkaline phosphatase had highly significant relationship with available $\mathrm{P}\left(\mathrm{r}=0.470^{* *}\right)$ rather than acid phosphatase $\left(r=0.399^{*}\right)$, indicated that alkaline phosphatase had greater contribution in the buildup of available $\mathrm{P}$ status of the soil in comparison to acid phosphatase activity. Organic amendments and associated plant residues may supply additional sources of la- bile $\mathrm{C}$ and $\mathrm{P}$ to the oil, which can stimulate microbial growth and biochemical activity (Carpenter-Boggs., et al. 2000).

Relationship between soil microbial variables and heavy metals

The data in table 6 revealed that the soil micro-flora had negative and/or non-significant relationship with all the heavy metals, except $\mathrm{Cu}$ and $\mathrm{Cr}$ which had significant relationship with actinomycetes and bacteria ( $r=0.356^{*}$ and $0.312^{*}$, respectively), indicated that the accumulation of heavy metals in these polluted soils as influenced by effluents released from the industries as well as mining activities had detrimental effect on soil microbes. Microorganisms are the first biota that undergoes direct and indirect impacts of heavy metals. Some metals (e.g. Fe, $\mathrm{Zn}, \mathrm{Cu}, \mathrm{Ni}, \mathrm{Co}$ ) are of vital importance for many microbial activities when occur at low concentrations. These metals are often involved in the metabolism and redox processes. Metals facilitate secondary metabolism in bacteria, actinomycetes and fungi [22,23]. Chromium is known to have stimulatory effect on both actinorhodin production and growth yield of the model actinomycetes. However, high concentrations of heavy metals may have inhibitory or even toxic effects on living organisms [24]. Adverse effects of metals on soil microbes result in decreased decomposition of organic matter, reduced soil respiration, decreased diversity and declined activity of several soil enzymes [25]. The toxic concentration of heavy metals may cause enzyme damage and consequently their inactivation, as the enzymes-associated metals can be displaced by toxic metals with similar structure [24]. Similarly, the soil enzyme activities also greatly influenced by the accumulation of heavy metals as indicated by negative and/or non significant relationship was observed between enzyme activities and heavy metals, except $\mathrm{Cr}$, which showed positive and significant relationship with microbial variables. The results indicated that increased levels of heavy metals in the soils of the present study caused deleterious effects on microbial activities that led to degradation of the soil quality. 
Assessment of Soil Microbes and Enzyme Activities in the Degraded Soils Adjacent to Industries and Mines and its Relation with Heavy Metal Contaminants

\begin{tabular}{|l|c|c|c|c|c|c|c|}
\hline Microbial variable & $\mathbf{F e}$ & $\mathbf{C u}$ & $\mathbf{M n}$ & $\mathbf{Z n}$ & $\mathbf{C r}$ & $\mathbf{N i}$ & $\mathbf{P b}$ \\
\hline Fungi & -0.172 & -0.152 & 0.082 & 0.037 & $0.343^{*}$ & -0.001 & -0.067 \\
\hline Bacteria & -0.092 & -0.092 & 0.095 & -0.099 & 0.150 & -0.040 & 0.159 \\
\hline Actinomycetes & -0.253 & 0.155 & -0.043 & $0.314^{*}$ & 0.051 & -0.022 & -0.042 \\
\hline DHA & -0.072 & $-0.318^{*}$ & 0.054 & 0.120 & $0.494^{* *}$ & 0.226 & -0.069 \\
\hline FDA & 0.042 & $-0.379^{*}$ & 0.161 & -0.027 & $0.628^{* *}$ & 0.180 & 0.073 \\
\hline Acid Phosphatase & 0.062 & $-0.330^{*}$ & 0.155 & 0.001 & $0.603^{* *}$ & 0.291 & 0.041 \\
\hline Alkaline Phosphatase & -0.039 & -0.165 & -0.033 & 0.196 & 0.273 & 0.266 & 0.137 \\
\hline
\end{tabular}

Table 6: Relationship (r) between soil microbial variables and heavy metals. *and"* Significant at 5.0 and 1.0 per cent level, respectively.

\section{Conclusion}

Heavy metals pose a significant threat towards the soil environment and the rapid industrialization will result in increasing problems of environmental pollution. Therefore, it is necessary to carry out the continuous monitoring of both industrial areas and their vicinities for possible transgressions of the limits given by the authorities. When necessary, the remedial measures should be applied as soon as possible by all available means. The soils adjacent to mining and industrial areas in some parts of Odisha contain toxic levels of $\mathrm{Fe}, \mathrm{Mn}, \mathrm{Cr}, \mathrm{Pb}$, and $\mathrm{Ni}$ limiting the productivity of various crops and these heavy metals suppress the soil enzyme activities. Accumulation of heavy metals due to mining activities and release of effluents from industrial areas and consequently their entry in to the soil-plant system is very much harmful and there is an urgent need to advocate proper remedial measures so as to minimize the levels of these toxic elements in the soil-plant-animal-human chain. On the other hand, research should be promoted to understand the mechanisms of microbial response to heavy metal pollution and to enable screening for possible resistant microorganisms that could be used for both remediation and restoration of soil environment fertility.

\section{Bibliography}

1. Wong SC., et al. "Heavy metals in agricultural soils of the Pearl River Delta, South China". Environmental Pollution 119.1 (2002): 33-44.

2. Tulay Ekemen Keskin. "Nitrate and heavy metal pollution resulting from agricultural activity: a case study from Eskipazar (Karabuk, Turkey)". Environmental Earth Sciences 61 (2010): 703-721.
3. McGrath SP., et al. "Plant and rhizosphere process involved in phytoremediation of metal-contaminated soils". Plant and Soil 232 (2001): 207-214.

4. Gisbert C., et al. "A plant genetically modified that accumulates $\mathrm{Pb}$ is especially promising for phytoremediation". Biochemical and Biophysical Research Communications 303 (2003): 440445.

5. Wyszkowska J and Wyszkowski M. "Effects of Cadmium and Magnesium on Microbial Activities in Soil". Polish Journal of Environmental Studies 11.5 (2002): 585- 591.

6. Pandey B., et al. "Effects of Coal Mining Activities on Soil Properties with Special Reference to Heavy Metals". In Geostatistical and Geospatial Approaches for the Characterization of Natural Resources in the Environment (Ed. Raju, N.). Springer, Cham (2016): 369-372.

7. Casida LEJr., et al. "Soil dehydrogenase activity". Soil Science 98 (1964): 371.

8. Chen ZQ., et al. "The effects of railway transportation on the enrichment of heavy metals in the artificial soil on railway cut slopes". Environmental Monitoring and Assessment 186.2 (2014): 1039-1049.

9. Karaca A., et al. "Effect of cadmium contamination with sewage sludge and phosphate fertiliser amendments on soil enzyme activities, microbial structure and available cadmium". Biology and Fertility of Soils 35.6 (2002): 428-434.

10. Hinojosa MB., et al. "Soil moisture pre-treatment effects on enzyme activities as indicators of heavy metal-contaminated and reclaimed soils". Soil Biology Biochemistry 36.10 (2004): 1559-1568. 
Assessment of Soil Microbes and Enzyme Activities in the Degraded Soils Adjacent to Industries and Mines and its Relation with Heavy Metal Contaminants

11. Green VA., et al. "Assay for fluorescein diacetate hydrolytic activity: Optimization for soil samples". Soil Biology and Biochemistry 38 (2006): 693-701.

12. Tabatabai MA and Bremner JM. "Use of p-nitrophenyl phosphate for assay of soil phosphatase activity". Soil Biology and Biochemistry 1 (1969): 301-307.

13. Jackson ML. Soil Chemical Analysis. $2^{\text {nd }}$ edition. Prentice Hall of India Pvt. Ltd., New Delhi (1973): 498.

14. Carreras HA and Pignata MAL. "Biomonitoring of heavy metals and air quality in Cordoba City, Argentina, using transplanted lichens". Environmental Pollution 117.1 (2002): 77-87.

15. Schnürer JS and Rosswall T. "Fluorescein diacetate hydrolysis as a measure of total microbial activity in soil and litter". Applied Environmental Microbiology 43 (1982): 1256-1261.

16. Dick RP. "Soil enzyme activities as integrative indicators of soil health". In Biological Indicators of Soil Health (Eds. Pankhurst, C.E., Doube, B.M., Gupta, V.V.S.R.), CAB International, Oxford, UK (1997): 121-156.

17. Kremer RJ and Jianmei Li. "Developing weed-suppressive soils through improved soil quality management". Soil and Tillage Research 72 (2003): 193-202.

18. Eivazi F and Tabatabai MA. "Phosphatases in soils". Soil Biology and Biochemistry 9 (1977): 167-172.

19. Zelles L., et al. "Effect of artificial irrigation, acid precipitation and liming on the microbial activity in soil of a spruce forest". Biology and Fertility of Soils 4 (1987): 137-143.

20. Frankenberger WT and Dick WA. "Relationships between enzyme activities and microbial growth and activity indices in soil”. Soil Science Society of America Journal 47 (1983): 945951.

21. Carpenter-Boggs L., et al. "Organic and biodynamic management: effects on soil biology". Soil Science Society of America Journal 64 (2000): 1651-1659.

22. Weinberg ED. "Roles of trace metals in transcriptional control of microbial secondary metabolism". Biology of Metals 2 (1990): 191-196.

23. Hafeburg G and Kothe E. "Microbes and metals: interactions in the environment". Journal of Basic Microbiology 47 (2007): 453-467.
24. Bruins MR., et al. "Microbial resistance to metals in the environment". Ecotoxicology and Environmental Safety 45 (2000): 198-207.

25. Tyler G. "Heavy metal pollution and soil enzymatic activity". Plant and Soil 41 (1974): 303-311.

\section{Assets from publication with us}

- Prompt Acknowledgement after receiving the article

- Thorough Double blinded peer review

- Rapid Publication

- Issue of Publication Certificate

- High visibility of your Published work

Website: www.actascientific.com/

Submit Article: www.actascientific.com/submission.php

Email us: editor@actascientific.com

Contact us: +919182824667 